Research Article

\title{
Contamination of water and soil of rice fields with soil transmitted helminths as source of transmission to farmers in Grogol sub-district, Kediri district
}

\author{
Siti Munawaroh ${ }^{1}$, Heny Arwati ${ }^{2 *}$, Puspa Wardhani ${ }^{3}$ \\ 1) Master Program in Basic Medical Sciences in Parasitology, Faculty of Medicine, Universitas Airlangga \\ 2) Department of Parasitology, Faculty of Medicine, Universitas Airlangga \\ 3) Department of Clinical Pathology, Dr. Hospital Soetomo / Faculty of Medicine, Universitas Airlangga
}

\begin{tabular}{ll}
\multicolumn{1}{c}{ A R T I C L E I N F O } \\
\hline Submitted & : Sepetember 2019 \\
Accepted & : December 2019 \\
Published & : January 2020 \\
\hline
\end{tabular}

\section{Keywords:}

Water, soil, feces, soil transmitted helminths

\section{*Correspondence:}

heny-a@fk.unair.ac.id

\begin{abstract}
Soil-transmitted helminths (STH) are the worms which transmitted through the soil. The people of Dusun Semen, Grogol, Kediri have a habit of defecating in the river. Farmers who work in direct contact with water and soil are possible to be infected with STH. The purpose of this study was to investigate the contamination of water and soil of the rice field with STH by identifying the species of STH in water, soils, and farmers' fecal samples to find out the transmission to the farmers. Water samples were collected from three spots of river A and B, soil samples from 43 rice fields, and fecal samples from 50 farmers. Water samples were examined by sedimentation, soil samples by floatation, and fecal samples by Kato-Katz method. The data were then analyzed by Chi square test. Out of 18 water samples, 12 samples $(66.7 \%)$ were positive, consisted of 4 samples $(22.2 \%)$ contained Ascaris lumbricoides, and 8 samples (44.4\%) contained Trichuris trichiura. Total soil samples were 129, where 8 samples $(6.2 \%)$ were positive for $A$. lumbricoides, and 10 samples $(7.7 \%)$ for $T$. trichiura. Out of 50 farmers, only 39 gave the fecal samples, where 12 samples $(31.0 \%)$ were positive consisted of 5 samples (12.8\%) for $A$. lumbricoides, 8 samples $(20.5 \%)$ for T.trichiura. Two species of STH found in the media of water, soil, and feces of farmers were A. lumbricoides and T. trichiura. Positive farmers' samples prove STH transmission from STH contaminated water and soil of rice fields.
\end{abstract}




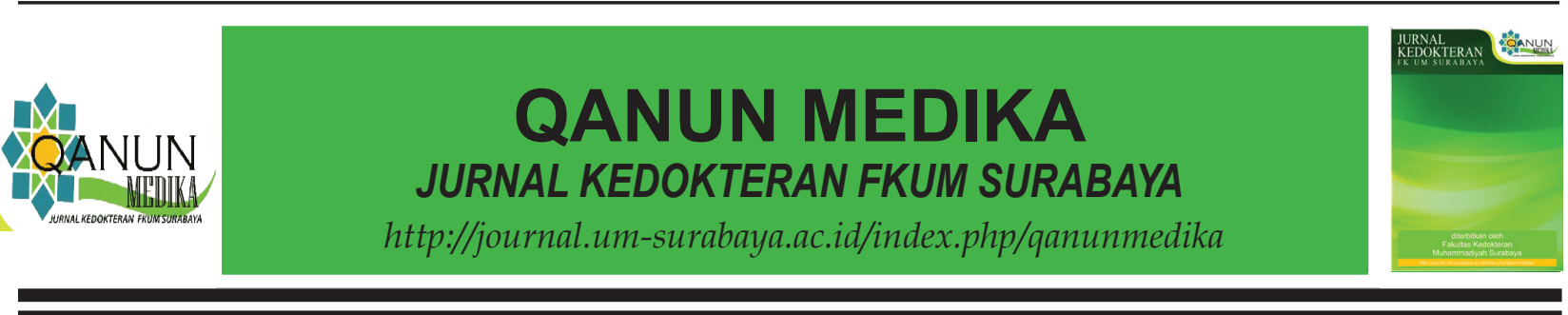

\section{INTRODUCTION}

Soil-transmitted helminths (STH) are the worm those transmitted through the soil. The cases of worms' infections become a significant problem for world health, where more than 1.5 billion people or $24 \%$ of the total population worldwide infected with STH (WHO, 2012). The STH infections affect the poorest and most deprived communities. These worms are transmitted by the eggs present in human feces, which in turn contaminate the soil in areas where sanitation is poor. The main species that infect people are roundworm (Ascaris lumbricoides), whipworm (Trichuris trichiura) and hookworm (Ancylostoma duodenale and Necator americanus). Infections are widely distributed in tropical and subtropical areas, with the greatest numbers occuring in Sub-saharan Africa, the America, China, and East Asia (WHO, 2019). The current comprehensive prevalence rate of STH in Indonesia is difficult to be ascertained. The prevalence rate in children is higher than in adults due to poor personal hygiene (Lee \& Ryu, 2019). Indonesia has more than 60 million cases of ascariasis and trichuriasis, and 60 million cases of hookworm infection (Hotez \& Ehrenberg, 2010).

The people of Dusun Semen, Grogol Subdistrict, Kediri District in East Java Province, Indonesia, have a habit of defecating in the river that may contaminate the water with STH. When the contaminated water is used to irrigate the rice fields, it may contaminate the soil of rice fields. Farmers are one group that has a high risk infected by helminths. In the daily activities, they do not use any personal protective equipment or PPE (Prayitno, Hanafi, \& Sholihah, 2017) such as glove and boots, in direct contact with contaminated water and soil are possible to be infected by STH (Winita, Mulyati, \& Astuti, 2012). The biggest risk of wastewater irrigation in agriculture is to helminth infections due to their long survival in the environment (Amoah, Adegoke, \& Stenstrom, 2018).

The purpose of this study was to investigate the contamination of water and soil of rice field with STH by identifying the species of STH in water and soils microscopically, and followed by examination of fecal samples of the farmers to find out the STH transmission through those media.

\section{METHOD}

The study was an observational analytic study with a cross-sectional approach. The water samples were collected by quota sampling method from two different rivers, river $\mathrm{A}$ and B from there sample were collected from 3 spots of each river (Singarimbun, 1989). The sampling method for soil sample was total sampling, where the samples were collected from a total 43 rice fields. Soil samples were then collected from 3 spots of each rice field (Yeshaneh, 2015). The fecal samples were collected by total sampling method from 50 farmers who were residing in the village and working in those rice fields. This research has passed the ethical test with ethics certificate number: 208/EC/KEPK/FKUA/2019 issued by the Faculty of Medicine, Universitas Airlangga.

Table 1. Location of water sampling

\begin{tabular}{lcl}
\hline Name of river & Name of spot & Location on the river \\
\hline $\mathrm{A}$ and $\mathrm{B}$ & $\mathrm{A} 1$ and $\mathrm{B} 1$ & At the base of the entry of water to the village \\
& $\mathrm{A} 2$ and $\mathrm{B} 2$ & Between A1 and before entering the rice field \\
& $\mathrm{A} 3$ and B3 & At the point of the entry of water to the rice field \\
\hline
\end{tabular}




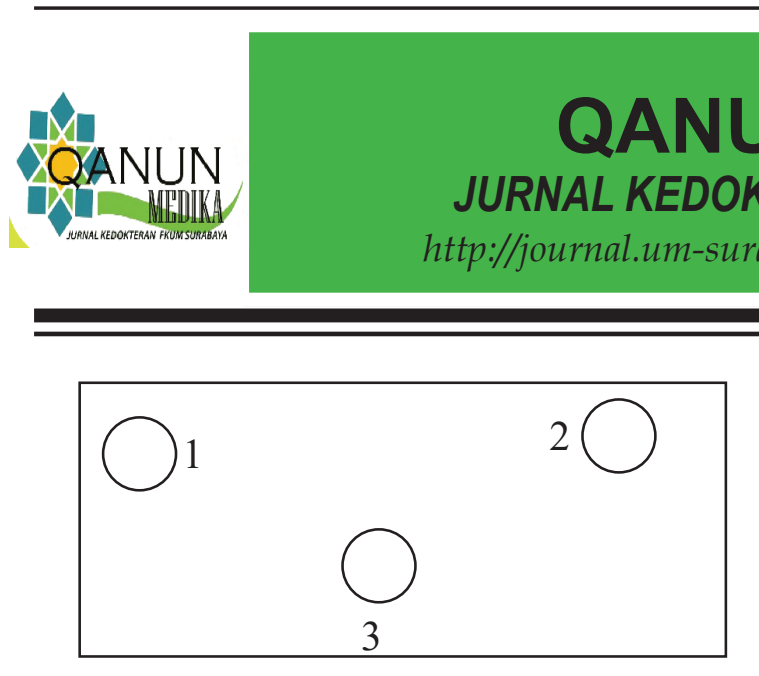

Figure 1. Soil sampling point

\section{Soil sampling procedure}

The types of soil based on the texture of the rice field soil in the study area are sandy and clay. Each rice field was divided into three spots, as shown in Figure 1. Spot one and two were at the corners of field, and spot 3 was at about the middle of the field.

The spots of sample collection were cleaned from the grass. Soil samples were collected from the surface of the rice field by scraping using a plastic spoon because eggs or larvae spread on the surface of the soil. Surface soil was scraped off at the spot $\pm 40 \times 40 \mathrm{~cm} 2$ depth and $\pm 30 \mathrm{~cm}$ width as much as \pm 100 grams. The samples were stored in sample-pots of $5 \mathrm{~cm}$ in diameter, closed tightly, and protected from the sunlight by carrying in an icebox, then sent to the Laboratory of Parasitology, Bhakti Wiyata Institute of Healthy Science in the district of Kediri.

\section{Fecal sampling procedure}

An explanation of the current research was delivered to the farmers and provided the sign of informed consent prior to fecal sample collection. About 2-5 grams of solid feces or $10-15 \mathrm{ml}$ of diarrhea stool or half the volume of the pot were collected in the morning before working in the rice fields (WHO, 1991). The farmers were also asked to fill the questionnaire. Samples were examined immediately on the same day; otherwise, the hookworm eggs will be damaged or hatch into larvae. If this is not possible, then the feces were pored with $5-10 \%$ formalin until the time of examination.

\section{Sedimentation method for water samples examination}

The water sample was transferred into a 15 $\mathrm{ml}$ centrifuge tube and was centrifuged at $1500 \mathrm{rpm}$ for 2 minutes. The supernatant was removed. One drop of sediment was then placed on a glass object; eosin was added, and covered with a cover glass. Slides were then observed under a light microscope with the magnification of 100x and 400x.

\section{Floatation method for soil samples examination}

A five grams sample was transferred into a 100 $\mathrm{ml}$ of beaker glass containing saturated $\mathrm{NaCl}$ solution and stirred well. The sample was then transferred into a glass tube until convex then covered with a cover glass and allowed to stand for 30-40 minutes. The cover glass was then placed on an object-glass prior to light microscopy examination.

\section{Kato Katz Method for fecal samples examination}

A gram of fecal sample was taken with a stick and placed on filter paper and then put wire mesh on the feces. Cardboard that has been perforated was placed on the glass object. The wire mesh was placed on top of the feces; then, the cardboard holes were filled with feces, and cardboard was removed. Feces on object glass was then covered with cellophane that has been soaked in the Kato solution. Cellophane tape was pressed with other glass objects to flatten the stool, and it was left for 20 - 30 minutes at room temperature. Objects glass was then examined under a light microscope using a 10x objective lens, and the number of worm eggs was counted. 


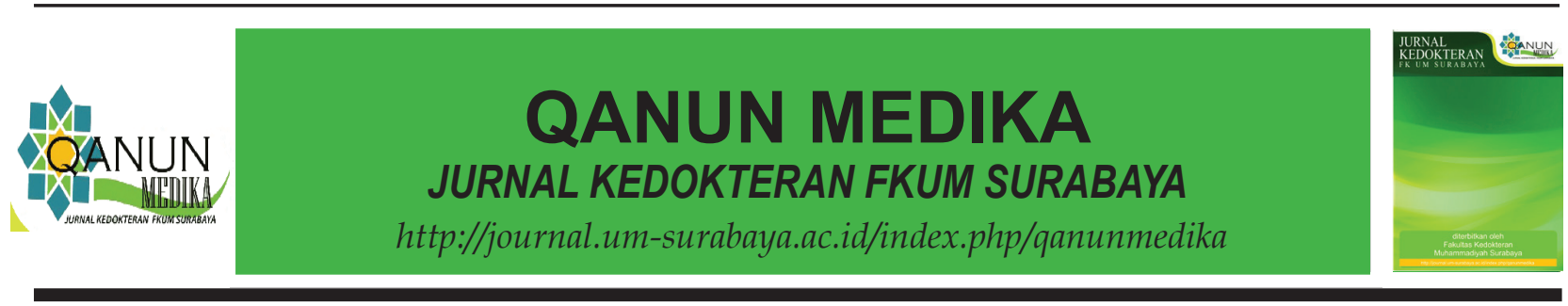

\section{RESULTS}

\section{The Characteristic of Participants}

The total number of farmers who gave the fecal samples was 39, where 19(49\%) were male farmers, and $20(51.85 \%)$. The ages of participants were group into 25-35 years old were $15(38 \%)$, and $46-45$ were $24(62 \%)$. Out of 39 samples, $12(30.77 \%)$ were found infected with STH, consisted of 7(36.84\%) male and $5(25 \%)$ female.
Microscopy examination of water, soil and fecal samples

The results of light microscopy examination of water, soil, and feces were presented in Table 2. The number of positive water samples was 6 (66.7) from either river A or river B. More positive samples were found in sandy soils $(19.0 \%)$ than in clay $(9.1 \%)$. Positive fecal samples were $12(31.0 \%)$ less than negative samples which were $27(69.0 \%)$.

Table 2. Number of positive and negative samples in each sampling area

\begin{tabular}{lccc}
\hline \multirow{2}{*}{ Area } & \multicolumn{2}{c}{ Number (\%) } & \multirow{2}{*}{ Total (\%) } \\
\cline { 2 - 3 } & Positive & Negative & \\
Water samples & $6(66.7)$ & $3(33.3)$ & $9(50.0)$ \\
River A & $6(66.7)$ & $3(33.3)$ & $9(50.0)$ \\
River B & $\mathbf{1 2 ( 6 6 . 7 )}$ & $\mathbf{6}(33.3)$ & $\mathbf{1 8 ( 1 0 0 )}$ \\
Total & & & \\
Soil samples & $12(19.0)$ & $51(81.0)$ & $63(50.0)$ \\
Sandy & $6(9.1)$ & $60(90.9)$ & $66(50.0)$ \\
Clay & $\mathbf{1 8 ( 1 4 . 0 )}$ & $\mathbf{1 1 1}(\mathbf{8 6 . 0})$ & $\mathbf{1 2 9}(\mathbf{1 0 0})$ \\
Total & $12(31.0)$ & $27(69.0)$ & $39(100)$ \\
Fecal samples & $\mathbf{4 2}$ & $\mathbf{1 4 4}$ & $\mathbf{1 8 6}$ \\
Fecal samples & & & \\
\hline Total & & & \\
\hline
\end{tabular}

Table 3. Distribution of STH species in water, soil, and fecal samples

\begin{tabular}{lccc}
\hline \multirow{2}{*}{ Kind of sample } & \multicolumn{2}{c}{ Number (\%) } & \multirow{2}{*}{ Total } \\
\cline { 2 - 3 } & A. lumbricoides & T. trichiura & \\
\hline Water samples & $2(33.3)$ & $4(66.67)$ & 6 \\
River A & $2(33.3)$ & $4(66.67)$ & 6 \\
River B & $\mathbf{4 ( 3 3 . 3 )}$ & $\mathbf{8 ( 6 6 . 7 )}$ & $\mathbf{1 2}$ \\
Total & & & \\
Soil samples & $7(58.3)$ & $5(43.7)$ & 12 \\
Sandy & $1(16.7)$ & $5(53.3)$ & 6 \\
Clay & $\mathbf{8 ( 4 . 4 )}$ & $\mathbf{1 0}(59.6)$ & $\mathbf{1 8}$ \\
Total & $4(33.4)$ & $8(66.6)$ & 12 \\
Fecal sample & $\mathbf{4 ( 3 3 . 4 )}$ & $\mathbf{8 ( 6 6 . 6 )}$ & $\mathbf{1 2}$ \\
\hline Total & & & \\
\hline
\end{tabular}


Table 4. Prevalence of STH species in water, soil, and fecal samples

\begin{tabular}{lcccc}
\hline \multirow{2}{*}{ Type of sample } & \multicolumn{2}{c}{ Number (\%) } & \multirow{2}{*}{ Negative } & \multirow{2}{*}{ Total } \\
\cline { 2 - 3 } & A. lumbricoides & T. trichiura & & \\
\hline Water samples & $2(22.3)$ & $4(444)$ & $3(33.4)$ & 9 \\
River A & $2(11.1)$ & $4(222)$ & $3(33.4)$ & 9 \\
River B & & & & \\
Soil samples & $7(11.1)$ & $5(7.9)$ & $51(81.0)$ & 63 \\
Sandy & $1(1.5)$ & $5(7.5)$ & $60(91.0)$ & 66 \\
Clay & & & & \\
Fecal samples & $4(10.3)$ & $8(20.5)$ & $27(69.2)$ & $\mathbf{3 9}$ \\
Fecal samples & $\mathbf{1 7}$ & $\mathbf{2 6}$ & $\mathbf{1 4 3}$ & $\mathbf{1 8 6}$ \\
\hline \multicolumn{1}{c}{ Total } & & & &
\end{tabular}

Twelve $(66.7 \%)$ out of 18 water samples were positive, consisted of 4 samples $(22.2 \%)$ as A.lumbricoides which 2 (33.3) out of them distributed either in river A or river B. Eight samples $(44.4 \%)$ were found containing T.trichiura, which 4 (66.7) was distributed either in river $A$ or river B. Seven positive samples $(58.3 \%)$ of A. lumbricoides were found in sandy soil and 1 $(16.7 \%)$ in the clay of paddy fields. The eggs of T.trichiura were found in five samples $(43.7 \%)$ in sandy soil and five samples (53.3\%) in clay. Of the 39 faecal samples, 12 samples $(31.0 \%)$ were positive, consisted of 4 samples (33.4 $\%)$ for A.lumbricoides, 8 samples (66.6\%) for T.trichiura. The results of the Chi Square analysis showed that there was a relationship between STH species found microscopically in water, soil, and feces. The distribution of STH species was shown in Table 4.

\section{DISCUSSION}

The STH infection in children has received more attention than in farmers as shown by the implementation of deworming and providing albendazole treatment to school children in Indonesia (Sungkar, Ridwan, \& Kusumowidagdo, 2017), even though STH can infect people in all age groups (Novianty, Dimyati, Pasaribu, \& Pasaribu, 2018) including the farmers (Amoah \& Stenstrom, 2018; Apsari, Arwati, \& Dachlan, 2019).
The investigation of water, the soil of rice fields, and fecal samples of the farmers in Grogol Sub-district, Kediri District, which was previously suspected as transmission media of STH among the farmers, has been proved by the finding of STH species in all those samples sources. Based on examination of 18 water samples using the sedimentation method found four samples $(22.2 \%)$ containing A.lumbricoides eggs and eight samples (44.4\%) containing eggs T.trichiura and negative results are six samples $(33.33 \%)$. These results showed that the water in the rice fields has been contaminated with STH because the water to irrigate the rice fields came from the river used for defecation by the villagers. This behavior is resulting in the biological hazard like STH that contaminated the water and soil of rice fields. The positive fecal samples collected from the farmers who work without any PPE, such as boot, gloves, and shoes, indicated the STH transmission has occurred through the water and soils where they work every day. The use of PPE was indeed important to protect the transmission of STH among the farmers and other workers who work in direct contact with soil. A study in Barito Kuala District, South Kalimantan Province, Indonesia, showed that the farmers who did not use complete PPE were more at risk of infection by helminth eggs than the farmers use complete PP (Prayitno et al., 2017). 


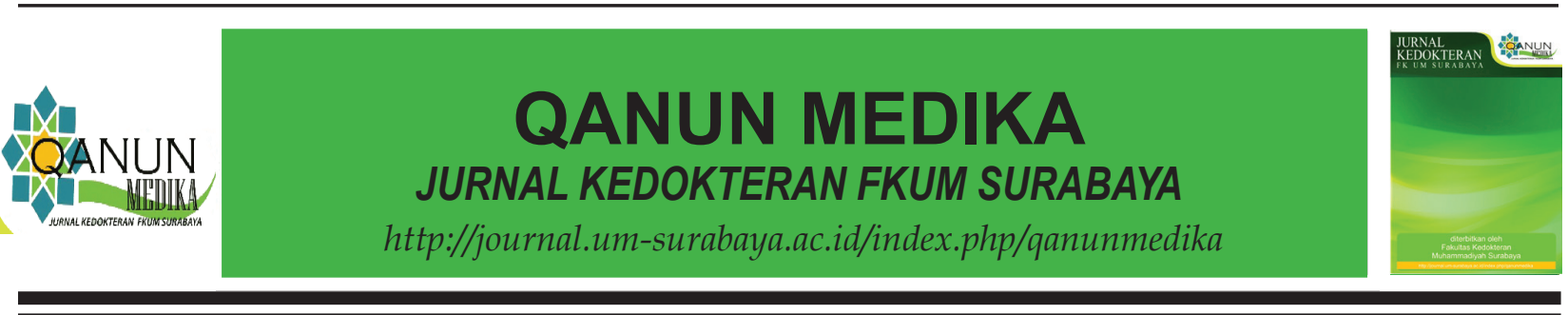

Usually, during lunchbreak, the farmers washed their hands before and after lunch using the same water that uses to irrigating the rice fields without soap, then continue working again after lunc break. Handwashing using contaminated water without soap during a lunch break is one way of STH transmission from hand to mouth.

The different source of STH transmission has been found in Hanam Province of northern Vietnam where the infection of $A$. lumbricoides (24\%) and T. trichiura (40\%) related to the use of wastewater and excreta in agriculture (Pham-Duc et al., 2013). The STH transmission among vegetable farmers in Ghana related to the wastewater irrigation used to water the crops, which proved by the finding of STH positive samples collected from wastewater, soils, and stools of farmers and their family members (Amoah et al., 2018).

Human behavior that often pays little attention to the importance of using clean water for life contributes to the occurrence of STH infection. This can lead to a reduced balance between the population and the environment. As a result, the condition of environmental sanitation is bad, and disease transmission can occur quickly. Environmental health is closely related to the problem of lack of clean water facilities that risk to the transmission of STH. River water contaminated with worm eggs is often used for various purposes and activities such as defecation, watering vegetable plantations, bathing, and washing. Soil is the primary medium of STH transmission because their transmission cannot occur without passing the soil. The STH distribution depends on fecally contaminated environment containing STH eggs. Soil contamination, especially by A.lumbricoides eggs, occurs mostly in rural areas, suburban areas, and urban areas that are densely populated (Suriptiastuti, 2006).
Temperature is critical to track the STH to continueits life cycle. Each species has a different optimum temperature. For the development of A.lumbricoides eggs in the soil can develop into infective eggs require a temperature of $20^{\circ} \mathrm{C}-25^{\circ} \mathrm{C}$, T.trichiura approximately $30^{\circ} \mathrm{C}$ and $N$.americanus require optimal temperatures between $28^{\circ} \mathrm{C}-32^{\circ} \mathrm{C}$. Humidity also an essential factor for maintaining worm life. If humidity is low, A.lumbricoides and T.trichiura worm eggs will not develop properly, and worm larvae will die quickly (Bethony et al., 2006).

Another factor that plays a role as supporting the development and distribution of STH worms is the type and nature of soil particles. The development of A. lumbricoides and T. trichiura eggs require clay, moist, and protected from sunlight. Contrary, the larvae of hookworms require oxygen for their growth. The most suitable and beneficial type of soil for hookworm is sand, loose, humus, and protected from direct sunlight (Mabaso, Appleton, Hughes, \& Gouws, 2004; Brand, 1973) Therefore, no hookworms were found in this research area, because hookworms prefer sand soil (Bethony et al., 2006), while the soil in this study was clay and sand mixed soil.

There were only two species of A.lumbricoides and T.trichiura found in either water, soil and feces of farmers. Chi-square test which showed a relationship between samples of water, soil, and feces of farmers with a significance value of $p=0.000$, indicated that there was a relationship among those sources of samples. This result proves that water and soil are a medium of transmission for STH infections in farmers. The farmers who defecate in the river, feces containing STH eggs pollute the river's water then contaminate the soil. Healthy farmers can also acquire STH infection if they work in this contaminated paddy field. This chain of STH transmission will continue if there are no changes in their habit in defecating manner and must be involving the government's 
participation. The enlightenment about STH infections includes the way of infection, transmission and treatment, not defecating in the river, the importance of PPE when working in the fields, and washing hands and feet using soap and running water that is not contaminated with STH before eating. The procurement of family toilets or public toilets is also important. All that can be done if researchers or residents work together with the relevant government.

\section{CONCLUSION}

The presence of STH eggs, especially $A$. lumbricoides and $T$. trichiura in the water, soil, and fecal samples of the farmers, proved the chain of transmission among those three media. By enlightenment about STH infection, transmission and administration, and the importance of using PEE during working in the field, followed by the treatment of STH-infected villagers, will reduce or break the transmission.

\section{ACKNOWLEDGEMENT}

The authors gratefully thank the Institute of Health Sciences Bhakti Wiyata Kediri for allowing us to use the facilities for this research.

\section{REFERENCE}

Amoah, I. D., Adegoke, A. A., \& Stenstr€om, T. A. (2018). Soil-transmitted helminth infections associated with wastewater and sludge reuse: a review of current evidence. Tropical Medicine and International Health, 23(7), 692-703.

Apsari, P. I. B., Arwati, H., \& Dachlan, Y. P. (2019). Correlation of total IgE level and intensity of infection among soil transmitted helminthiasis farmers in Klungkung Regency, Bali, Indonesia. Folia Medica Indonesiana, 55(2).

Bethony, J. rey, Brooker, S., Albonico, M., Geiger, S. M., Loukas, A., Diemert, D.,
\& Hotez, P. J. (2006). Soil-transmitted helminth infections: ascariasis, trichuriasis, and hookworm. The Lancet, 367.

Brand, T. Von. (1973). Biochemistry of parasites (2nd ed.). Academic Press. New York and London.

Hotez, P. J., \& Ehrenberg, J. P. (2010). Escalating the global fight against neglected tropical diseases through interventions in the Asia Pacific region. Advances in Parasitology, 72, 32-48.

Lee, J., \& Ryu, J.-S. (2019). Current status of parasite infections in Indonesia: A Literature Review. Korean J Parasitol, 57(4), 329-339.

Mabaso, M. L. H., Appleton, C. C., Hughes, J. C., \& Gouws, E. (2004). Hookworm (Necator americanus) transmission in inland areas of sandy soils in KwaZuluNatal, South Africa. Tropical Medicine and International Health, 9(4), 471-476.

Novianty, S., Dimyati, Y., Pasaribu, S., \& Pasaribu, A. P. (2018). Risk factors for soil-transmitted helminthiasis in preschool children living in farmland, North Sumatera, Indonesia. Journal of Tropical Medicine, 2018.

Pham-Duc, P., Nguyen-Viet, H., Hattendorf, J., Zinsstag, J., Phung-Dac, C., Zurbrügg, C., \& Odermatt, P. (2013). Ascaris lumbricoides and Trichuris trichiura infections associated with wastewater and human excreta use in agriculture in Vietnam. Parasitology International, 62(2), 172-180.

Prayitno, H., Hanafi, A. S., \& Sholihah, Q. (2017). Factors associated with helminthiasis among vegetable farmers in Barito Kuala District. Asian J. Epidemiol, 10(3), 108-115. 


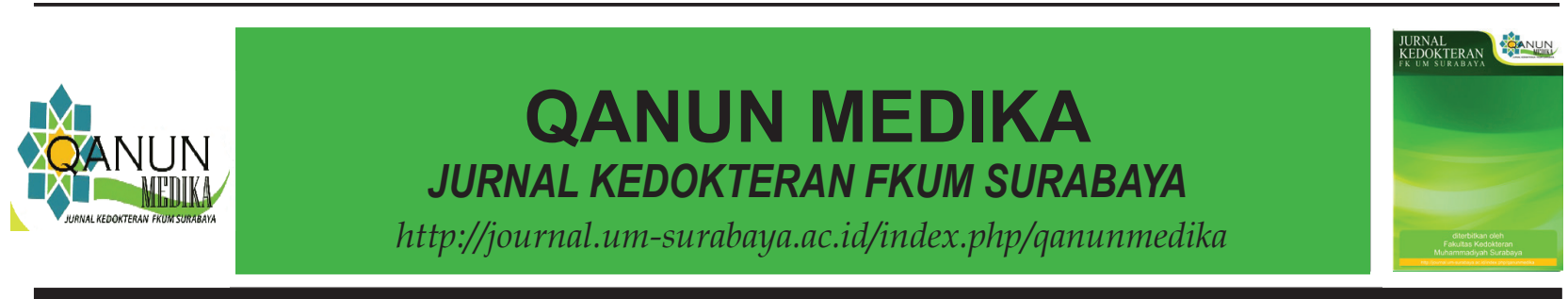

Sungkar, S., Ridwan,A.S., \& Kusumowidagdo, G. (2017). The effect of deworming using triple-dose albendazole on nutritional status of children in Perobatang Village, Southwest Sumba, Indonesia. Journal of Parasitology Research, 2017.

Suriptiastuti. (2006). Infeksi soil-transmitted helminth: ascariasis, trichiuriasis dan cacing tambang. J. Universa Med, 26, 84-93.

WHO. (1991). Basic laboratory methods in medical parasitology. World Health Organization, Geneva. Geneva.

WHO. (2012). Soil-transmitted helminthiases: STH : eliminating soil-transmitted helminthiases as a public health problem in children : progress report 2001-2010 and strategic plan 2011-2020. World (D. A. Montresor, ed.). Geneva.
Winita, R., Mulyati, \& Astuti, H. (2012). Upaya pemeberantasan kecacingan di sekolah dasar. Makara Kesehatan, 16(2), 65-71.

Yeshaneh, G. T. (2015). Assessment of soil fertility variation in different land uses and management practices in Maybar Watershed, South Wollo Zone, North Ethiopia. International Journal of Environmental Bioremediation \& Biodegradation, 3(1), 15-22. 